\title{
Manners as Desire Management
}

\section{Anja Berninger ${ }^{1}[$}

Published online: 24 April 2020

(C) The Author(s) 2020

\section{Introduction}

Is behaving politely towards others morally valuable? Or are manners merely conventional rules which make social interaction run more smoothly without fulfilling any deeper ethical role? Even though the 'value of manners' is far from a mainstream topic in contemporary philosophy, there have lately been some efforts to afford manners a more important role in the moral debate. ${ }^{1}$ Thanks to the writings of Amy Olberding and other scholars of Chinese philosophy, Confucian approaches have also played a central part in this renewed discussion. ${ }^{2}$

This paper aims to contribute to this debate, but not by offering a completely new perspective on why manners might be morally relevant. Rather, my goal is to add to the discussion by focussing on the moral psychology of manners. I want to better understand what sorts of changes learning and behaving in accordance with good manners initiate in us. This may seem like a matter that is merely peripheral to the discussion. However, in my view, those wishing to defend the moral importance of manners need to provide a plausible account of such changes. Most importantly, they need to explain how good manners are not only a tool that allows us to avoid social sanctions for impolite behavior, but rather that learning good manners profoundly changes who we are.

\footnotetext{
1 See Sarah Buss, "Appearing Respectful: The Moral Significance of Manners," Ethics, Vol. 109, No. 4, (1999): 795-826; Cheshire Calhoun, "The Virtue of Civility," Philosophy \& Public Affairs, Vol 29, No. 3, (2000): 251-275; Karen Stohr, On Manners (New York: Routledge, 2012).

2 See Amy Olberding, "Etiquette: A Confucian Contribution to Moral Philosophy," Ethics, Vol 126. No. 2, (2016): 422-446; Erin M. Cline, "The Boundaries of Manners: Ritual and Etiquette in Early Confucianism and Stohr's on Manners," Dao, Vol. 15, No. 2, (2016): 241-255; Bryan W. van Norden, "Principles, Virtues, or Detachment? Some Appreciative Reflections on Karen Stohr's on Manners," Dao, Vol. 15, No. 2, (2016): 227-239; Amy Olberding, The Wrong of Rudeness: Learning Modern Civility from Ancient Chinese Philosophy (New York: Oxford University Press, 2019).
}

Anja Berninger

anja.berninger@philo.uni-stuttgart.de

1 Institute of Philosophy, University of Stuttgart, Seidenstr. 36, 70174 Stuttgart, Germany 
This suggests that the moral psychology of manners needs to be further spelled out, especially since relatively little work has been done on the issue. ${ }^{3}$ Those who defend the ethical importance of manners tend to claim that being polite somehow changes us for the better in the long-run, but they often fail to expand much further on this very general claim. ${ }^{4}$ They thus leave a host of questions unanswered. Most importantly, they fail to explain what sorts of changes are initiated through learning polite behavior and why these changes should affect us at our very core.

In this paper, I will develop a perspective on these issues which heavily draws on the work of the Chinese philosopher Xunzi. The idea, however, is not to see Xunzi as a historical figure whose work needs detailed interpretation. Rather, I propose to treat Xunzi as akin to the central figures of Western philosophy. In other words, I want to develop a Xunzian position just as other contemporary philosophers develop Humean or Kantian positions. This undertaking will involve sketching some of Xunzi's central assumptions (all of which I take to be plausible) and to then develop a position based on these assumptions.

The position I defend will be compatible with Xunzi's theory of manners, while making important additions to the overall picture he painted. Xunzi does not develop a detailed position on the psychological resources involved in acquiring manners or on the question of how they shape our inner selves. In discussing these potential resources my aim is thus to further develop the position that he advances along lines that are consistent with the central tenets of his theory, but that are also informed by current reflections in moral psychology and philosophy of mind.

Approaching Xunzi's work in this way opens new avenues for a systematic reflection on his work. It allows us to see Xunzi not exclusively as a figure of historical interest, but rather to also reflect on how his philosophical positions and their further development can contribute to current day theorizing in ethics and moral psychology. It thus allows us to take a step towards developing a truly integrative account of manners and their relevance to moral psychology.

I will take up two central Xunzian assumptions in this paper: First of all, Xunzi voices the intuition that humans are endowed by nature with certain desires and that these desires have morally problematic aspects. Second, Xunzi suggests that manners and polite behavior are important remedies to these problematic tendencies. I will spell out these intuitions in the first section of the paper and argue that they are indeed plausible.

\footnotetext{
3 There are some notable exceptions. Thus Olberding and Wong both claim that feedback-loops between body and mind play a central role here. However, as will become clear later in the paper, I think that this cannot account for all of the changes that manners supposedly cause. See Amy Olberding, op. cit. 2019; David B. Wong, "Cultivating the Self in Concert with Others." In Amy Olberding, ed., Dao Companion to the Analects, (Dordrecht: Springer Netherlands, 2014), 171-197. Winnie Sung has also published a text on the psychological relevance of manners in the Xunzi, but aims more at clarifying Xunzi's theory than defending a systematic position on these issues. See Winnie Sung, "Ritual in the Xunzi: A Change of the Heart/Mind," Sophia, Vol. 51, (2012): 211-226.

4 A good example for this strategy can be found in Kant, who claims that politeness is an outward sign of benevolence and respect. Even though such signs may be "empty at first", according to Kant they may lead to "real dispositions of this sort" in the long-run. Immanuel Kant, Anthropology from a Pragmatic Point of View, trans. and ed. by Robert B. Louden (Cambridge: Cambridge University Press 2006), p. 44.
} 
I will use the second section of the paper to introduce the aforementioned claim that manners may change our behavior without making us morally better. Here, I will mainly focus on the claim that well-mannered behavior might be understood as a mere means to satisfying desire that changes our psychological make-up but does not reshape us into ethically better human beings. They thus might improve our actions, by making us less prone to harming others, but these changes are brought about for strategic rather than ethical reasons. I call these changes merely superficial changes and distinguish them from the profound changes that Xunzi had in mind. I also discuss which criteria must be met in order for some change in our psychology not to be merely superficial in this sense.

In the third section of my paper, I then discuss how to further articulate the Xunzian position so as to align with these demands. I explain how several accounts which immediately spring to mind are untenable. I then proceed to sketch what I take to be the most convincing explanation of how manners modify our psychological make-up. Acquiring good manners, I will claim, essentially involves habituating certain patterns of attention. This acquisition fundamentally changes our psychological make-up for the better by allowing us to manage the problematic desires with which we are endowed by our biological nature.

\section{Desires and Why We Need to Manage Them - A Xunzian Perspective}

Let us start off the discussion by examining Xunzi's position on desire and human nature. Xunzi is famous for proposing the view that human nature is deeply problematic. In this respect his position differs from that of other Confucian philosophers such as Mencius. In a much-quoted passage Xunzi states:

People's nature is bad. Their goodness is a matter of deliberate effort. Now people's nature is such that they are born with a fondness of profit in them. If they follow along with this, then struggle and contention will arise, and yielding and deference will perish therein. They are born with feelings of hate and dislike in them. If they follow along with these, then cruelty and villainy will arise, and loyalty and trustworthiness will perish therein. They are born with desires of the eyes and ears, a fondness of beautiful sights and sounds. If they follow along with these, then lasciviousness and chaos will arise, and ritual and $y i$, proper form and order, will perish therein. Thus, if people follow along with their inborn dispositions and obey their nature, they are sure to come to struggle and contention, turn to disrupting social divisions and order, and end up becoming violent. So, it is necessary to await the transforming influence of teachers and models and the guidance of ritual and $y i$, and only then will they come to yielding and deference, turn to proper form and order, and end up becoming controlled. ${ }^{5}$

\footnotetext{
${ }^{5}$ Xunzi, Xunzi: The Complete Text, trans. and ed. by Eric L. Hutton. (Princeton: Princeton University Press, 2016), p. 248.
} 
The term "people's nature" is often misunderstood and calls for some clarification. It is a translation of the Chinese term xing (性), which is generally assumed to have been used in early Chinese texts to describe the direction of growth and the natural tendencies of a living being. ${ }^{6}$ Furthermore, the Xunzi explicitly opposes it to the term wei (偽) which refers to that which is brought about through deliberate effort. ${ }^{7}$ So, we can say that the term xing is used to portray our natural dispositions and the way in which our actions develop spontaneously if they are left unguided. ${ }^{8}$

In this passage Xunzi stresses the destructive potential of xing. Most importantly, he highlights the negative aspects of (some of) our inborn dispositions, especially our desires. Desires, as he understands them here, are seen as part of our biological makeup and as such they are neither learned nor acquired in any way. According to Xunzi, desires are object-directed states which reside directly in our sense organs. They are focused on sensual objects such as food and drink, but also more complex goods such as material gain and the avoidance of harm. ${ }^{9}$ Overall, Xunzi thus only considers a relatively narrow segment of desires, namely those which seem to be similar to what we call cravings or urges. He certainly does not maintain that all of the desires we might potentially develop are problematic, but rather restricts his negative view on this small group of biologically given orectic states.

There is some debate among scholars of Chinese philosophy as to whether these desires are directly action motivating or not. Since I only want to draw on some very fundamental Xunzian intuitions, I will not enter into this complex textual debate. ${ }^{10}$ For the purposes of this paper, I will simply accept the (relatively) uncontroversial claim that desires in the Xunzian sense have a strong influence on our actions without stating whether this influence is direct or indirect. Human beings which have not learned to manage their impulses tend to simply go along with their desires. Thus, these individuals have a strong tendency to unreflectively put their desires for food, drink and material benefit into practice.

While Xunzi's conception does not map neatly unto contemporary conceptions of desire, it does not stand in stark contrast to common assumptions about the matter. We can use the the important distinction between desires as "trying to get something" and the idea of desires as the subject's being "genuinely attracted to a desired object" to

\footnotetext{
${ }^{6}$ See Winnie Sung, "Mencius and Xunzi on Xing (Human Nature)," Philosophy Compass, Vol. 11, No. 11, (2016): 632-641, Kwong-loi Shun Mencius and Early Chinese Thought (Stanford: Stanford University Press, 1997), p. 37.

${ }^{7}$ See Winnie Sung, "Mencius and Xunzi on Xing (Human Nature)," Philosophy Compass, Vol. 11, No. 11, (2016): 632-641.

${ }^{8}$ Obviously, there is more to be said on the exact understanding of xing both in Xunzi and in his contemporaries. For an overview of these debates see Winnie Sung, "Mencius and Xunzi on Xing (Human Nature)," Philosophy Compass, Vol. 11, No. 11, (2016): 632-641. For a detailed discussion of xing both in Mencius and in Yangist philosophy, see Kwong-loi Shun, op. cit.

9 See Chris Fraser, "Happiness in Classical Confucianism: Xúnž̌," Philosophical Topics, Vol. 41, No. 1, (2013): 53-79.

${ }^{10}$ Winnie Sung has provided and excellent overview and in-depth discussion of this issue. See Winnie Sung, "Yu in the Xunzi: Can Desire by Itself Motivate Action?," Dao, Vol 11, No. 3, (2012): 369-388.
} 
further refine this conception. ${ }^{11}$ According to the Xunzi desires and actions can come apart, that is, we can have desires, but not act on them. Thus, we may desire to go on living, but, under certain circumstances, we may willingly choose death and act accordingly. ${ }^{12}$ From this we can conclude that Xunzi must have the second understanding of desires in mind. If I am thirsty, for instance, I find the idea of having a drink genuinely attractive without therewith already trying to get a drink (though there is a strong tendency to put that desire into action).

It seems clear from the passage quoted above that the problem of desires is not that they are always directed at morally bad things or states of affairs. Nothing is morally wrong per se with desiring things such as food and drink or my own benefit. The destructive potential of our bodily impulses does not rest in the objects they aim at. Rather, as Xunzi highlights, problems arise because of our tendency to go along with our desires (i.e. to put the desire in question into action). Because desires are not rooted in idiosyncratic individual preferences, but are rather part of our basic biological make-up, all humans will desire the same sorts of things. And, assuming we live in a world with limited resources, this, in turn, is likely to lead us into conflict with one another. There simply would not be enough resources to fulfil all existing desires. The negative consequences do not arise from the desires themselves but rather from our unthinkingly going along with them.

The negative aspects of desires are not limited to the fact that they often bring us into conflict with one another. A further aspect comes to light when we think about the perspective we have on the world in the state of nature Xunzi describes. Because our basic desires take center stage in our mental economy, we focus exclusively on ourselves and the fulfilment of our own needs. This egocentric perspective makes it impossible for us to develop and uphold social relations (and the related feelings of trust and loyalty). As long as we do not manage our bodily impulses, we remain largely isolated creatures who look at the world from a purely egocentric perspective. ${ }^{13}$

Xunzi develops his account of desires in direct opposition to Mencius, who assumed that humans are endowed with inherent dispositions which tend to develop in good ways if properly cultivated. According to Mencius there is a natural tendency in humans towards morally good actions, which, however, needs to be properly cultivated. ${ }^{14}$ This opposition partially explains the very strong wording of (some segments) of the chapter on human nature in the Xunzi. In developing a Xunzian

\footnotetext{
${ }^{11}$ Chris Heathwood, "Which Desires Are Relevant to Well Being?" Noûs, Vol. 53, No. 3, (2019): 664688.

12 Xunzi, op. cit, p. 244.

13 The issue of egocentricity is also highlighted by Olberding and Sung. See Amy Olberding, The Wrong of Rudeness: Learning Modern Civility from Ancient Chinese Philosophy (New York: Oxford University Press, 2019), Winnie Sung, Xin in the Xunzi, (PhD Thesis, University of New South Wales 2010); Winnie Sung "Ritual in the Xunzi: A Change of the Heart/Mind," Sophia, Vol. 51 (2012): 211-226.

14 Note, however, that current scholarship suggests that the relationship between the two positions is more complex, because the two philosophers frame the scope of "human nature" rather differently. For an overview of this debate see Winnie Sung, "Mencius and Xunzi on Xing (Human Nature)," Philosophy Compass, Vol. 11, No. 11, (2016): 632-641. For a comparison of Chinese and Western approaches see Eric Schwitzgebel, "Human Nature and Moral Education in Mencius, Xunzi, Hobbes, and Rousseau," History of Philosophy Quarterly, Vol. 24, No. 2, (2007): 147-168.
} 
position, however, there is no need to fully endorse every detail of his description. We do not need to share his assumption that human nature is bad (full stop). Rather, we can settle for the much more plausible position that our biological make-up endows us with some basic bodily impulses and that these impulses (if completely unmanaged) lead to ethical problems. This can occur, just as Xunzi says, firstly, because our impulses push us towards acting in ways that are bound to bring us into conflict with others and, secondly, because they confine us to an egocentric perspective that places the self at the very center.

This more moderate reading is also consistent with textual evidence. Sweeping claims about xing are limited to a relatively narrow set of textual passages in the Xunzi. The claim that human inherent dispositions are bad is prominent throughout chapter 23 of the text, but is not really developed in other sections. Recently, scholars have come to suggest that this chapter is a collation of several arguments both on human desires and on the importance of rituals and artifice. The claim that our dispositions are bad serves as a refrain within this collation and aims at binding the sections closer together. ${ }^{15}$ We can thus conclude that in addition to being a more plausible position, the nuanced view suggested is also consistent with current interpretations of the text. ${ }^{16}$

It initially seems plausible that manners and rituals (as important rules of social interaction) play a central role in controlling our desires ${ }^{17} \mathrm{~A}$ vast proportion of what counts as basic, well-mannered behavior concerns impulse control, e.g. manners tell us not to eat the whole cake when we are invited to a wedding (even if we would like to), they also demand that we only drink from our own glasses at a dinner party and that we sit still in a movie theatre even if we feel the urge to run around. So, it does initially seem plausible that acquiring good manners is directly connected to impulse control.

Obviously, this is only a prima facie kind of plausibility. In order to show that manners can be central in managing our desires, as Xunzi himself suggests, we need to say much more about the way in which they do so. Before turning to questions and issues that arise with respect to moral psychology, my main field of interest in this paper, I want to provide a rough outline of how Xunzi further articulates his position. In doing so, I will limit myself to explicating those aspects of his theory on which I assume there to be a relatively broad interpretational consensus among scholars of Chinese philosophy.

In developing his reflections on manners and rituals, Xunzi is concerned, first of all, with the societal chaos which would ensue if all humans were to unreflectively follow their natural dispositions. According to this view, such chaos can be

\footnotetext{
15 Dan Robins, "The Development of Xunzi's Theory of "Xing”, Reconstructed on the Basis of a Textual Analysis of "Xunzi 23", Xunzi "xing e" 性惡 ("Xing” is Bad)," Early China, Vol. 26/27, (20012002): 99-158.

16 Thanks are owed to an anonymous reviewer for alerting me to this aspect.

17 In the translation cited, the term "ritual" is used. Note, however, that in the Chinese original Xunzi uses the term $l i$ (禮), which has a relatively broad array of meanings including etiquette, manners, ritual and general rules of propriety. For the purposes of this text, I leave these other connotations aside and simply see the term $l i$ as referring to manners.
} 
prevented through drawing and upholding social distinctions (fen; 分). The human ability to make distinctions is thus a key ingredient for creating a functioning social structure. A well-ordered society for Xunzi is one in which we distinguish different social roles and in which the members of society interact in accordance with their assigned roles. ${ }^{18}$ Thus, according to the Xunzi there are certain behavioral standards that we e.g. demand of teachers and these differ from those that we place on students. Extending from the examples the Xunzi provides we can also say that we demand certain acts from the host of a dinner party and other acts from the invited guests. Here we see how manners come into the picture. Following the demands of well-mannered behaviors is what creates societal order.

Manners are not limited to bringing about and sustaining outer order, however. Rather, scholars have made the plausible claim that Xunzi also sees manners as making a difference to our psychological make-up. According to the Xunzi participating in ritual also has the effect of profoundly changing our outlook. Part of this process consists in refocusing us away from our own self-interest. In other words, we can see Xunzi as suggesting that there is indeed a connection between manners and moral psychology. ${ }^{19}$

\section{Superficial and Deep Transformations}

Xunzi assumes that both the societal and the inner transformations associated with good manners necessarily go hand in hand with one another. If a society becomes well-ordered, then individuals will behave according to certain roles and this in turn means that they will no longer be primarily motivated by self-interest. Yet, prima facie, one may wonder whether this belief in the necessary coupling of the two transformations might not be a bit too optimistic. The following case comes to mind: I might fulfil my roles as a teacher, father, husband and so on, simply because society demands it of me. In other words, my primary interest in fulfilling these roles is to avoid being negatively sanctioned. Upon further reflection I may also see that fulfilling these roles allows me the long-run maximum desire satisfaction I can expect, given the current circumstances. In such a case, I would outwardly act the part (e.g. behaving in ways that are expected of a good teacher, father etc.), but I would do so not because I have replaced the focus on my personal benefit through a more inclusive ethical perspective, but because

\footnotetext{
${ }^{18}$ See Xunzi, op. cit., 30. For an in-depths analysis of fen and its importance in the Xunzi see Behuniak and Goldin, on whose positions I draw here. See Paul Rakita Goldin, Rituals of the Way (Chicago: Open Court, 1999). James Behuniak, "Nivison and the Problem in Xunzi's Ethics," Philosophy East and West, Vol. 50, No. 1, (2000): 97-110. For an interpretation of Confucian positions more generally speaking as well as a further development of these positions that puts special attention on the importance of roles see Roger T. Ames, Confucian Role Ethics: A Vocabulary (Hong Kong: The Chinese University Press, 2011).

${ }^{19}$ See Winnie Sung, "Ritual in the Xunzi: A Change of the Heart/Mind," Sophia, Vol. 51 (2012): 211226.
} 
I have come to conclude that my long-term benefit can be maximized through these actions. I am thus still a desire-driven egocentric being, but one that is able to prioritize long-term interests. Thus, one can say that I am transformed through roles and their related manners, but that from an ethical perspective the transformation is quite shallow. ${ }^{20}$

Xunzi could respond that these cases do not really involve a proper endorsement and thus not a proper fulfilment of the roles in question. He might claim that, if I really fulfil my role as a teacher then my focus will not be primarily on the satisfaction of my own desire (independent of the question of whether it is long-term or short-term). One might add that my actions are truly in accordance with the demands of good manners only in this case. When I continue pursuing my own benefit, it may seem to the casual observer that I display good manners, but this would be a misjudgement. ${ }^{21}$ The same is also true of the societal order. A society may seem well-ordered upon a first glance, yet this would be a false impression so long as people have not fully endorsed their respective roles.

Similarly, Xunzi could also claim that someone who is only beginning to learn how to act appropriately may continue to see the world according to how it relates to his or her self-interest. But as time progresses the person will more and more come to fully embrace the roles in question, shifting his or her outlook away from the previously dominant, narrow self-interest. Again, the central point is that the proper, full fulfilment of roles and the related well-mannered behavior will also incorporate a shift in outlook.

In summary, according to Xunzi, we simply cannot maintain our original selfish outlook, while fully adopting roles and good manners. According to his view, a change in perspective and the adoption of good manners always go hand in hand. But, even if we read Xunzi as rejecting the idea they might come apart out of hand, the fact that these cases are imaginable still brings up interesting questions regarding the moral psychology of manners. Thus, it shows that we ought to clarify what the differences are between deeper and merely superficial changes in psychological

\footnotetext{
20 This option is modelled on Sung's discussion of the role of the heart-mind in the Xunzi. She discusses and ultimately rejects the idea that personal satisfaction is the goal of the heart-mind (and that following certain ethical standards is just a way of maximizing this satisfaction) (Winnie Sung, Xin in the Xunzi (PhD Thesis, University of New South Wales, 2010), pp. 122-123). Nivison suggests that consequentialist reflections about maximum desire satisfaction (according to Xunzi) are indeed instrumental in making us focus on ethical demands in the first place, but that once we follow them, we also come to find them valuable in themselves (David Nivison, The Ways of Confucianism. Investigations in Chinese Philosophy (Chicago: Open Court, 1996), pp. 209-210).

21 An example for the second type of case can be found in chapter 31 of the Xunzi. There we find a brief discussion of cases, where someone might appear well-mannered at first sight, but may still not fully adhere to ritual practices. See Xunzi, op. cit., p. 333. Note, also, that Xunzi is aware of the fact that we often engage in pretend-play when we act within ritualistic contexts such as e.g. funeral rites (See Mark Berkson, "Xunzi's Reinterpretation of Ritual: A Hermeneutic Defense of the Confucian Way," in T. C. Kline and Justin Tiwald, eds., Ritual and Religion in the Xunzi, (Albany: State University of New York Press, 2014), pp. 107-132). The sort of pretend-play envisaged here is not really a form of hiding inner dispositions. Rather, there are subtle differences between the way we act within rituals and every-day actions. It thus seems clear that everyone involved is aware of the distinction between the two.
} 
make-up. ${ }^{22}$ How should the deep transformation be described in detail? What are the psychological resources involved in these changes?

Xunzi himself provides us with some bits of information as to how he thinks the transformation takes place by highlighting, for instance, that practice and habituation have a central role to play in the process. ${ }^{23}$ But, unfortunately, he is far less clear as to how this ought to be spelled out in detail. Partly because of these uncertainties in interpretation, I would like to shift the perspective. My aim is not to spell out what Xunzi actually says on the issue, but to identify psychological resources and changes that plausibly make a difference here. Nothing that I say in what follows will go against Xunzi's actual position. But, as will become clear in the next section, I assume that in answering these questions we need to resort to psychological capacities that Xunzi himself did not explicitly mention. One might thus say that I want to provide a plausible extension of what Xunzi himself has to say by using the resources of current moral psychology.

Before I proceed with looking at potential ways in which the transformation could take place, I want to spell out some of the basic conditions that must be fulfilled so that we would say that a proper (not merely a superficial transition) in our mental make-up has occurred. Not just any change in our psychology will allow us to avoid the superficiality claim; rather, we need transitions of a certain kind to do so. Thus, manners must be psychologically transformative in the sense of changing some basic attitudes or an overall outlook. We can also say that they must transform our outlook in such a way that they truly change our relation to our own self-interest (e.g. not only making us more prudent in the pursuit of that self-interest). Secondly, manners must change us in a way which displays stability across time. We would not understand someone as truly transformed who only occasionally acts and feels in some way or another. Rather, any change needs to persist through longer stretches of time (years or perhaps even a whole lifetime) to count as non-superficial. Furthermore, the initiated changes must persist across a range of situations. It is not enough for manners to reign in our desires in certain highly specific contexts (such as e.g. when we have dinner with our new boss). Rather, they must do so across a wide range of different situations. Only then can we plausibly claim the initiated transition is not merely superficial. The challenge is thus to develop an account of manners according to which acquiring good manners (a) enables us to manage our desires in ways that allow us to avoid those issues highlighted in the Xunzi and (b) allows us to manage our desires in more than a merely superficial way.

\footnotetext{
${ }^{22}$ In developing this point, I owe much to Stalnaker's description of these issues. He rightly stresses that "ritual for Xunzi is not something that one engages in occasionally, but rather a style or mode of existence which permeates all of our activities and social interactions." (Aaron Stalnaker, "Transforming the Self: Confessions and Performance in the Thought of Augustine and Xunzi," in Brian Brown, John Doody, Kim Pfaffenroth, eds., Augustine and World Religions (Lanham: Rowman and Littlefield, 2008), p. 258.)

${ }^{23}$ See Xunzi, op. cit., 65. The importance of habits and skills in Chinese philosophy more generally speaking is also stressed by Fraser. See Chris Fraser, "Action and Agency in Early Chinese Thought," Journal of Chinese Philosophy and Culture, Vol. 5, (2009): 217-239.
} 


\section{Spelling Out the Transformation Claim}

If we are to uphold the transformation claim and the Xunzian perspective on manners, we need some plausible way of explicating how exactly manners bring about the kind of stable transformation that I outlined above. From what has been said so far we can clearly see that the changes in question need to consist in some way of managing our basic desires. In section one we identified two problems brought about by basic desires: they make it likely that we run into conflicts with others and they endow us with a purely egocentric perspective on the world. A proper form of desire management needs to deal with both of these issues.

Prima facie, there are various kinds of changes in our moral psychology that would allow us to deal with these problems. At least three options come to mind:

(a) We could change our mental make-up by eliminating the desires in question.

(b) Our mental make-up could be changed not by eliminating the desires, but by changing them in some significant way.

(c) The changes could be brought about not by manipulating the desires themselves, but by changing the relation in which we stand to our desires.

I will now discuss each of these options in detail. As I will show, only the third option allows for a plausible explication of the transformation claim.

Let us start by considering the first option, namely, the idea that manners eliminate our desires. I think that this position can be dealt with relatively quickly. Xunzi firmly objects to this solution. ${ }^{24}$ Thus, he explains:

All those who say that good order must await the elimination of desires are people who lack the means to guide the desire and cannot handle the mere having of desires. All those who say good order must await the lessening of desires are people who lack the means to restrain desire and cannot handle abundance of desires. $^{25}$

Indeed, the rejection is sensible. As discussed above, Xunzi's position does not focus on all kinds of desires, but rather only on the very basic bodily desires that are directly linked to our biological make-up (i.e. desires that we have for biological reasons). They result from the way our bodies are built. But, the nature of these desires gives us reason to doubt we could ever be successful in eliminating them. There simply seems to be no way in which we can get rid of desires such as the want for food and drink simply by learning the rules of polite behavior. With that we can already rule out option (a) as implausible.

\footnotetext{
${ }^{24}$ The claim that we cannot change our desires is also stressed by Kurtis Hagen. See Kurtis Hagen, "Xunzi and the Prudence of Dao: Desire as the Motive to Become Good," Dao, Vol. 10, No. 1, (2011): 53-70. However, Hagen also makes clear that there are some passages in the Xunzi where the author seems to suggest that we can change our nature, which seems to indicate that we actually can amend the desires themselves. Because I am not primarily concerned with interpretational issues, I will not go deeper into these problematic passages.

25 Xunzi, op. cit., p. 243.
} 
Let us proceed to consider solution (b), the idea that we should not eliminate desires, but rather that they should be transformed in some way. Some authors have suggested that this is the view Xunzi himself defends.

Thus, Kline provides us with the following interpretation:

Desires are the responses of dispositions to our environment. For example, going without liquids for many hours causes thirst, and we desire something to drink. If we are able to form new dispositions, then we will in effect also be forming the sources of new desires, desires that aim toward the objects of our approvals [...], and not simply toward benefit and harm. According to Xunzi, through reforming our dispositions we will be, among other things, elevated above the crude preferences of our digestive tract. Consider again the disposition of thirst. We are born with a rather crude disposition aimed at finding any drink that can satisfy our thirst. As we become educated in the ritual order [...], we perform repeated intentional acts of drinking particular drinks, in particular situations, in certain ways. [...] What was a crude disposition becomes a disposition to drink certain drinks in ritually prescribed situations and manners. These dispositions in turn produce desires to drink in such a manner when the situation presents itself, desires that are in accord with ritual practice. No longer do our desires simply track the reactions of our mouth and belly. They now accord with the understanding and approvals developed through ritual activity. ${ }^{26}$

I am not so much interested in the question of whether this constitutes a correct interpretation of the Xunzi. My aim is to develop a plausible account of the moral psychology of manners, accepting Xunzi's negative outlook on the nature of desires and his general account on manners, while also suggesting that we need to give some additional account of the transitional role of manners. Therefore, I do not want to discuss whether Kline's interpretation is faithful to the text of the Xunzi. Rather, I am concerned with the question of whether this would be a plausible position to defend.

At first glance, it may seem as if Kline's reading really does present us with such a plausible solution. Manners often do prescribe ways in which we should or should not satisfy our desires. For example, if I am invited to a formal dinner party, as a well-mannered guest I am allowed to quench my thirst with water and white wine, but certainly not with a chocolate chip milkshake. Manners also suggest that I can quench my thirst with any drink I am served, but not with the drink of the person sitting next to me. Furthermore, rehearsing these sorts of actions on a regular basis may change some of our dispositions. Thus, when I habitually have wine at a dinner party and act as if I really like having wine (though deep down in my heart I might initially have wanted a milkshake instead) I may end up actually having a positive emotional reaction towards being served wine on such occasions. ${ }^{27}$ Thus, outward

\footnotetext{
26 T. C. Kline III, “The Therapy of Desire in Early Confucianism: Xunzi,” Dao, Vol. 5, No. 2, (2006): p. 242.

27 The potential relevance of these sorts of feedback-mechanisms for Confucian theories have also been stressed both by Olberding and Wong. See Amy Olberding, The Wrong of Rudeness: Learning Modern Civility from Ancient Chinese Philosophy (New York: Oxford University Press, 2019), Wong, op. cit.
} 
actions and responses may lead to positive emotional reactions and these can facilitate the sort of emotional refinement Kline has in view.

Despite its initial plausibility, I do not think we should rely on Kline's solution for further spelling out the Xunzian position we are aiming for. In my view, it is an insufficient response to the problems highlighted above. First of all, it is not clear whether the suggested changes to our moral psychology really concern our desires. Rather, Kline's account seems to make use of two different understandings of the term "desire" that ought to be kept apart: firstly, a basic sort of bodily reaction (which is thirst) and then, secondly, acquired preferences as to how to quench that thirst. When I attend a state dinner, I will preferably drink water and wine instead of milkshakes, and preferably I will drink from my own glass. But, this does not seem to change the desire as such. I am still thirsty and my thirst is directed at any drinkable fluid that is available (independent of whose glass it is in). So, really, we do not seem to be changing basic desires here so much as we are acquiring additional preferences. $^{28}$

Secondly, Kline's proposed solution is inadequate because it does not solve the issues highlighted in the earlier sections of this paper. If we assume that manners primarily influence us in the way Kline describes, they would perhaps be instrumental in limiting outer conflicts. But, the egocentricity problem would remain unresolved. Manners would not in any way help us in taking a more inclusive perspective on the world. My preferring white wine to milkshakes and my own glass to that of my neighbor would not in any way compel me to take others' perspectives into account or broaden my own perspective in any other useful way. I am still as egocentric as before, even if my desires prove less harmful in my interaction with others. Thus, it seems that solution (b) (at least in the form offered by Kline) is unpersuasive.

With this, let us then turn to the third option, that is, the idea that while a desire persists unchanged our relation to it can be altered. This, again, needs to be further spelled out. A first way of doing so would consist in assuming that we take a stance with respect to our desires by forming some higher-order attitude directed at them. Prima facie plausible candidates would be attitudes which result from our higherlevel deliberations. Thus, we might think about whether the desire in question is acceptable to have, how we might best fulfil it without causing inconvenience to others and so on. The attitudes resulting from these forms of deliberation might overrule our basic desires. Manners might be relevant here, because they provide us with some initial indication of how to evaluate our desires and might give us some idea of how we might be able to fulfil it (such as highlighting that we should only drink from our own glass).

Upon first glance, this solution seems to useful in that it lets us see both how we can stop the unfortunate influence of basic desires on our actions, while also opening the way towards not being limited to our own egocentric perspectives. It also

\footnotetext{
${ }^{28}$ Hutton also suggests in his translation of the Xunzi that what is changed is not the desire, but rather the way in which the desire is expressed in action. See Xunzi, op. cit., p. 65, footnote 46.
} 
shows how we can distance ourselves even from our most basic desires. So, this suggestion does seem to deal with the issues highlighted in the first section.

However, upon closer inspection a number of problems begin to arise. First of all, constant deliberation is cognitively demanding. If we need to deliberate about every single desire we have (so as to stifle our tendency to unreflectively put them into action), we would be cognitively stretched too thin. But this raises the question as to whether we could uphold this sort of very demanding activity across time and over a broad range of different situations. Especially, we might doubt whether reflection of this kind could persist, for example, under conditions of stress. So, it is not quite clear that this solution meets the demands that I highlighted above. But, even if it did, it would also lead to some rather undesirable changes in our psychology. This is brought out nicely by William James, when he writes:

There is no more miserable human being than one in whom nothing is habitual but indecision, and for whom the lighting of every cigar, the drinking of every cup [...] are subject to express volitional deliberation. Full half the time of such a man goes to the deciding or regretting, of matters which ought to be so ingrained in him as practically not to exist for his consciousness at all. ${ }^{29}$

James persuasively argues that we can only function well, if we do not deliberate about every step we take. But, if we take every single one of our desires as requiring intense reflection, then we are potentially putting ourselves in that exact situation. Every single step would then be an arduous task and subject to intense reflection. Constant deliberation of this kind would not make us better, but would rather probably just prevent us from taking any action at all. But, clearly, desire management from a Xunzian perspective should lead to better actions, not inactivity. So, we can conclude that deliberation informed by the rules of well-mannered behavior does not present us with a viable solution to the problems discussed above.

But, then, what other mental processes might be relevant given that constant deliberation is too cognitively demanding? In response to this question, we can again take up a suggestion from James. Thus, in the passage quoted above, he suggests that habits are crucial for guiding our everyday actions while avoiding the pitfalls of constant deliberation. James does not, however, discuss how habits might be relevant for coping with our own desires. So, the question arises whether James' view can be extended. Indeed, there is reason to think that habits also transform our relation to our own desires, but not through constant conscious reflection. If, for instance, I have the habit of never eating anything before 9 o'clock in the morning, I may still feel hungry at some earlier point in time. Nevertheless, if the habit is firmly ingrained, I may automatically resist the urge to eat. The idea of having breakfast now may not even cross my mind, simply because the habit is so well-entrenched. So, habits can be relevant because they stop us from mindlessly putting desires into action. They make our desires seem less relevant to us. And, thus, we can conceive of them as a form of desire management.

${ }^{29}$ William James, The Principles of Psychology: Volume One (New York: Dover Publications, 1950), p. 122. 
Many of our habitual actions are indeed dictated by the demands of good manners. To give only a few examples, we may say "sorry" when stepping on someone's foot or we may hold open the door for someone, not because we reflected on these actions, but simply out of habit. Saying "sorry" is just the way we are now disposed to react to accidentally stepping on someone's foot. Manners can thus be conceived of instilling certain habits in us, which in turn allow us to properly manage our desires by breaking the link between basic desires and action. They do so without forcing us to deliberate about every single step.

This does not mean that we need to completely exclude deliberation from the picture. Rather, we might think that deliberation is still relevant, even in this view, in the sense that I need to reflect upon the importance manners have for me and to make a commitment to act in accordance with them in addition to habituating certain patterns of action. ${ }^{30}$

There are reasons to question whether habits of this sort present us with a superior form of desire management. Many of the actions we do out of mere habit take on an absent minded, almost robotic quality. Thus, eating out of pure habit can result in my unthinkingly stuffing food into my mouth, just as my apologies for stepping on your foot may take on a robotic quality. I may not even notice that I have just apologized (and indeed my robotic apology may seem absolutely meaningless to you). Overemphasizing the importance of manners might thus introduce a different form of superficiality. It may seem as if the mere instilment of some habit of acting in a specific way is not the sort of deep transformation that we were seeking in the first place. Rather, all we get is some merely external, completely mindless way of acting. Furthermore, while we may make some headway towards keeping our egocentricity in check by distancing ourselves (and our actions) from our desires, it is not quite clear to what extent the perspectives of others find any inclusion in our outlook on the world. So, it again seems as if the egocentricity problem remains unsolved in this account.

The preliminary conclusion we can draw from this seems rather unfortunate. We cannot rely on the distanced stance which deliberation allows us to take with respect to our own actions. Nor can we assume that habitual actions based on the standards of good manners afford us the sort of inclusive perspective needed to counter the negative effects of our basic desires (even though they do make these desires seem less important to us). So, it seems as though neither mindless habitual activity, nor constant deliberation are useful in spelling out the transformation claim. With neither bodily habits nor constant reflection giving us the solution we are aiming for, we seem to be left stuck in a bind.

A sideward glance at theorizing on rituals more generally speaking is helpful for working out a way of escaping from this conundrum. Most importantly for us, scholars within this field have also been interested in making the distinction between

\footnotetext{
${ }^{30}$ We can debate what comes first. Thus, one might think that it is only because I have habituated certain actions that I can come to understand the importance of certain ethical standards. For an in-depth discussion of this option and its relevance to the Xunzi see Winnie Sung, Xin in the Xunzi, (PhD Thesis, University of New South Wales 2010).
} 
mere habitual action and proper ritualistic action. Thus, Jonathan Smith notes that we should be careful not to equate religious rituals with mindless habits (though habituation does play a role in them), and then goes on to explain: "Ritual is, first and foremost, a mode of paying attention". 31

This reflection is helpful, because it places a cognitive ingredient which we have up to now ignored at centre stage, namely our capacity for distributing attention. Smith claims that rituals force us to direct our attention away from ourselves and towards the objects and relations relevant for the rituals in question. Something similar prima facie seems to be true of well-mannered behavior. Take the example of hosting a dinner party. Being a good host involves performing certain scripted actions (such as taking the guests' coats, making sure all the glasses are filled and so on). However, going back to William James' observation about habits, we would want to say that it is not enough for a good host to simply complete these ritualistic actions in a purely robotic fashion. Rather, a good host will direct her attention in certain ways, not others. Thus, she will mainly be focused on the well-being of her guests (not her own). For example, she will check whether their glasses are still full, whether there is enough food, whether her guests seem happy, whether the conversation is running smoothly and so on. If everyone involved is well-mannered, the guests of the party will also distribute their attention in line with their current role. Thus, they will be focused on assisting the host by also doing their fair share in the conversation and they will also try to reassure the host by indicating that they appreciate her efforts.

According to this view good manners involve playing certain roles (such as the role of the host or the role of the guest), and thus, this position connects back to the Xunzian perspective outlined earlier. To successfully play such roles, we need to act according to a script largely provided by the rules of etiquette. Furthermore, and this is the new ingredient in the picture, we also need to distribute our attention in ways appropriate to the roles we play. Roles are social in the sense that they connect us to others. They demand that we focus our attention not on ourselves, but rather on these others. Thus, in the example discussed, the host will shift his attention on his guests and their well-being, while the guests will focus their attention on the host and his efforts.

Attention can be actively directed towards one thing or another. Indeed, some have suggested that attention is one of the few mental capacities that we can actively steer. ${ }^{32}$ But, there is no need to be actively involved in the process. We can also habitually shift our attention in certain ways. After having hosted dinner parties for some time, I may, for instance, have internalized the role of being the host and the appropriate patterns of attention which come with it. Thus, when I now host a dinner

\footnotetext{
31 Jonathan Z. Smith, To Take Place: Toward Theory in Ritual (Chicago: University of Chicago Press, 1987), p. 103. This passage is also quoted by Kurtis Hagen in a paper on Ritual in the Xunzi. Hagen suggests a different reading, namely the idea that we have to pay attention to rituals themselves. See Kurtis Hagen, "Xunzi and the Nature of Confucian Ritual," Journal of the American Academy of Religion, Vol. 71, No. 2, (2003): p. 378.

32 See Galen Strawson, "Mental Ballistics or the Involuntariness of Spontaneity," Proceedings of the Aristotelian Society, Vol. 103, No. 1, (2003): 227-256.
} 
party my attention will automatically settle on the well-being of my guests without any further involvement from my side.

Acquiring these role-based habitual patterns of attention can also play a central role in managing our desires in several ways. In instantiating these patterns, our attention is drawn away from the desires themselves, and this may lead to our feeling them less acutely. For instance, I may feel tired while hosting a dinner party, but since my attention will be continually directed towards my guests and their wellbeing, the feeling of sleepiness will not be quite as present to me as in other situations (such as when I watch TV alone in my flat). The desire to go to bed will still be hovering in the background, and perhaps I will even be aware of it every now and again before my attention shifts back to my guests. Still, overall, the desire to sleep will not be as present to me as in cases where my attention is not directed outwards. In other words, we have reason to think that the habituation of certain patterns of attention associated with acquiring good manners makes a phenomenal difference in this case. ${ }^{33}$

But, the influence of the acquired patterns of attention is not limited merely to experiential aspects. Rather, modifications to our patterns of attention might also affect our actions. Attention does not only make some objects more salient to me. Rather, it also makes certain action options more available to me than others. ${ }^{34}$ If I continuously direct my attention at a water bottle on the table in front of me, then it seems that actions such as drinking from the bottle, pouring a glass of water from the bottle or moving the bottle to the left side of the table are much more salient to me than other potential actions (such as going for a swim or turning on the TV placed on the other side of the room). Thus, the way that my attention is currently distributed has direct impact on the actions I spontaneously undertake.

Both the changes in phenomenality and the shift in salient action options suggest that the patterns of attention associated with good manners guide our choices of actions. The actions in question however are not of the merely habitual, robotic kind discussed above. Rather, they are undertaken with attention being crucially involved. Furthermore, the changes initiated are instrumental in disrupting our tendency to unthinkingly act from our desires, as they allow us to distance ourselves from them. This does not mean that the desires in question simply vanish. Once my guests have all gone home, I may still find myself saying: "I was so tired. The one thing I really wanted to do the whole evening was go to bed".

\footnotetext{
33 This is in line with a suggestion that Hutton makes in his translation of the Xunzi. Thus, he suggests that according to Xunzi the basic desires remain present, but are not felt by the subject. See Xunzi, op. cit., p. 65 , footnote 47 . Furthermore, it should be noted that there are some passages in the Xunzi that hint at this change in perspective. Thus in chapter 23 Xunzi suggests: "Now if people are hungry and see food but do not dare to eat first, that will be because there are some to whom they will give way. If people are tired but do not dare to see rest, that will be because there are some for whom they will substitute themselves" (Xunzi, op. cit, p. 250). Although the resource of attention is not explicitly mentioned here, we can take the passage as hinting at the proposed change in attention distribution. Thanks are owed to an anonymous reviewer for pointing this out to me.

${ }^{34}$ For the general idea that attention is a necessary ingredient of action, because it allows us to choose between the different objects that we can act upon see Wayne Wu. "Confronting Many-Many Problems: Attention and Agentive Control," Noûs, Vol 45, No. 1, (2011): 50-76.
} 
Thus, the desire may have persisted throughout the entire evening, but because it remained in the background of my attention, it did not play a large role in my mental economy.

The attentional approach can solve the issues with which we were struggling in all of the other approaches discussed thus far. As we have seen, according to this approach, manners involve the habituation of certain patterns of attention which in turn are directly connected to the habituation of certain social roles (such as the role of a host). Taking up Xunzi's perspective on roles we can say that roles effective place us in relation with others. Spelling this out in terms of attention we can now say that the proper fulfilment of a role will involve placing one's attention not on oneself, but rather on others and their needs. And, this, in turn, allows us to see how manners might facilitate our taking a more inclusive outlook on the world. In line with our roles, our attention will not be directed exclusively at ourselves and our needs, but rather toward the needs of others with whom we relate. Thus, if we understand manners as working in this way then they do offer a way out of our egocentric predicament. ${ }^{35}$ So, we have good reason to think that the attentional approach to manners can fulfil the criteria listed above.

Furthermore, the position can also supply us with at least a hint as to how we can more clearly differentiate between cases where roles are fully adopted and cases where roles are only adopted in order to maximize the satisfaction of desires in the long-run. Thus, it is at least plausible to think that in the second case we need to make sure that we are perceived as fulfilling some specific role in order to avoid social sanctions. In the case where we fully endorse the role in question, however, how we are perceived is far less relevant. ${ }^{36}$ There are subtle differences in each case as to the way we will distribute our attention. Thus, in the case where the ultimate goal is to maximize desire satisfaction, our attention should be attuned to the reaction of our audience. Most importantly, we should be sensitive to cues which signal the extent to which they take us to be adequately fulfilling our role. If this is correct, then, crucially, we are still at the center of our attention, because we are only interested in how others respond to us. This, in turn, seems different when we focus on cases where we truly fulfil our roles. Here our attention will be shifted unto others and their needs, and not primarily on their responses to us.

\footnotetext{
35 The idea that shifts in attention have an important moral role to play and can to some extent counter our egocentric tendencies is also suggested by Iris Murdoch. See Iris Murdoch, The Sovereignty of Good (London, New York: Routledge 1970). For an interpretation see Christopher Mole, "Attention, Self and the Sovereignty of Good," in Anne Rowe, ed., Iris Murdoch: A Reassessment (Basingstoke, New York: Palgrave Macmillan, 2006). pp. 72-84.

36 It has some relevance because we need to be recognized in our roles (at least to some extent) so as to be able to fulfil them. Thus, if my students do not see me as their teacher at all, it will be impossible for me to actually be their teacher.
} 


\section{Conclusion}

In this paper, I have aimed to articulate and further develop some intuitions on the ethical importance of manners and their central role in our moral psychology as it was originally presented in the Xunzi. I have suggested that Xunzi was right in claiming that acquiring manners fundamentally changes our psychological make-up. However, I have also indicated that it is not at all easy to spell out this intuition in detail. According to my analysis, the most plausible elaboration of this position assigns a central role to the habituation of certain role-based patterns of attention. According to this view, acquiring good manners allows us to reform our psychology in two central ways: first of all, patterns of attention break the intimate link between our basic desires and our unreflective actions; secondly, they instil a view of the world in us which is more inclusive than the egocentric perspective rooted in our basic desires.

This conception leaves room for integrating a further observation about manners. Manners are certainly important ways of managing desires. But, this does not mean that desires (even for a well-socialized person) can never take center stage. Basic desires can become so strong that even the most well-mannered person is unable to uphold the habituated patterns of attention. No one on the verge of starvation will care much for the way in which his desire for food is satisfied. Even those with excellent manners might suddenly act selfishly in extreme situations. Manners manage and to some extent counterbalance the influence of our desires. But, they do not change our basic biological make-up. It is possible that desires still win the upper hand in the battle for attention and influence on action. We might thus say that manners form the basis of a second nature that, however, never completely extinguishes the first.

One might think that the position I have advocated here is uniquely relevant to some form of Chinese philosophy, but far less important when seen from a Western perspective. I think this is wrong. The Xunzi provides us with a plausible starting point, because it is particularly clear in its analysis of where the problems lie that manners are supposed to solve. But, Western philosophers wanting to bolster the importance of manners also need to provide some account of how manners shape the self. I hope that the argument I have developed above can function as a sort of blueprint which helps us better understand these transitional processes no matter whether our starting point lies in Eastern or Western approaches to manners.

Acknowledgements Open Access funding provided by Projekt DEAL. Large parts of this paper were written during a research stay at the University of Hong Kong. The research stay was financed by the Fritz Thyssen Foundation (Grant Number Az.50.18.0.012 PH) for which I would like to express my gratitude. Special thanks are owed to Chris Fraser and Eirik Lang Harris for discussing my research project with me and sharing their expertise both on the Xunzi and early Chinese philosophy more generally speaking. I would also like to express my thanks to the Philosophy Department of the University of Hong Kong for hosting me and to audiences at events in Hong Kong, Taipeh and Stuttgart at which earlier versions of this paper were presented.

Open Access This article is licensed under a Creative Commons Attribution 4.0 International License, which permits use, sharing, adaptation, distribution and reproduction in any medium or format, as long as you give appropriate credit to the original author(s) and the source, provide a link to the Creative 
Commons licence, and indicate if changes were made. The images or other third party material in this article are included in the article's Creative Commons licence, unless indicated otherwise in a credit line to the material. If material is not included in the article's Creative Commons licence and your intended use is not permitted by statutory regulation or exceeds the permitted use, you will need to obtain permission directly from the copyright holder. To view a copy of this licence, visit http://creativecommons.org/ licenses/by/4.0/.

Publisher's Note Springer Nature remains neutral with regard to jurisdictional claims in published maps and institutional affiliations. 